Proceedings

\title{
Theoretical investigation on selenium-based Frustrated Lewis Pairs ${ }^{\dagger}$
}

\author{
Gianluca Ciancaleoni * \\ Dipartimento di Chimica e Chimica Industriale, Università di Pisa, via Francesco Moruzzi 13, 56124, Pisa \\ (Italy); gianluca.ciancaleoni@unipi.it \\ + Presented at the 1st International Electronic Conference on Catalysis Sciences, 10-30 November 2020; \\ Available online: https://sciforum.net/conference/ECCS2020
}

Published: 10 November 2020.

\begin{abstract}
The Frustrated Lewis Pairs (FLP) concept recently demonstrated to be a powerful way to activate small molecules and promote a plethora of organic reactions without the help of transition metal-based catalysts. This strategy is based on simple combinations of Lewis acids and bases that are sterically or electronically hindered from forming classical Lewis acid-base adducts. Generally, the Lewis acid is a fluorinated compound of boron or aluminum, and the Lewis base is based in most cases on phosphorous, nitrogen or, seldom, oxygen. To the best of our knowledge, no attempt has been made to isolate, characterize and test in catalysis selenium-based FLP. In the present contribution, the interaction between sterically encumbered organoselenium compounds, as selenides and selones, and standard Lewis acids, as $\mathrm{B}\left(\mathrm{C}_{6} \mathrm{~F}_{5}\right)_{3}$ and less-fluorinated boranes, will be studied by DFT calculations and compared to the interaction present in already known P-based FLPs. Attempts will be made to find bench-stable FLPs, with the aim to simplify the experimental studies and encourage the possible applications to real systems. Energy Decomposition Analysis results are shown and discussed, showing that selenium-based FLPs are theoretically possible. For the most promising candidates, the products of the activation of small molecules $\left(\mathrm{H}_{2}\right.$ or $\left.\mathrm{CO}_{2}\right)$ will be theoretically optimized, in order to check if the reaction would be thermodynamically favored.
\end{abstract}

Keywords: Frustrated Lewis Pairs; Organoselenium compounds; DFT calculations; Fluorinated boranes

\section{Introduction}

It is known that Lewis acids (LA) and bases (LB) tends to form stable adducts, as $\mathrm{H}_{3} \mathrm{~N}_{-} \mathrm{BH}_{3}$, but it is also known that, in case of severely congested moieties, the corresponding adducts does not form, as in the case of 2,6-lutidine and ВМез.[1] Such a concept took the name of frustrated Lewis pair (FLPs) and initially it was considered a not productive scientific curiosity, even if it has been invoked to explain some non-classical reactions.[2] In 2006, Stephan and coworkers began to systematically investigate the reactivity of encumbered fluorinated boranes, as $\mathrm{B}_{(}\left(\mathrm{C}_{6} \mathrm{~F}_{5}\right)_{3}(\mathbf{a})$, in the presence of sterically hindered phosphines, as $\mathrm{P}(t-\mathrm{Bu})_{3} \cdot[3]$

In particular, they noted that, starting from the zwitterion $\mathrm{R}_{2} \mathrm{PH}\left(\mathrm{C}_{6} \mathrm{H}_{4}\right) \mathrm{BF}\left(\mathrm{C}_{6} \mathrm{~F}_{5}\right)_{2}$, the substitution of the fluoride with a hydride was quite easy, giving $\mathrm{R}_{2} \mathrm{PH}\left(\mathrm{C}_{6} \mathrm{H}_{4}\right) \mathrm{BH}\left(\mathrm{C}_{6} \mathrm{~F}_{5}\right)_{2}$. The thermolysis of the latter unsurprisingly produced $\mathrm{H}_{2}$ and the neutral phosphino-borane system, which can be considered a FLP because no sign of aggregation could be observed. More surprising was the discovery of the reaction reversibility: the neutral system is able to dissociate gaseous $\mathrm{H}_{2}$ at $25^{\circ} \mathrm{C}$ and without any transition metal, giving again the zwitterion.[4] Successively, also systems containing separate phosphines and boranes showed the ability to activate $\mathrm{H}_{2}$, with a variability that depends on the exact basicity and acidity of the two moieties.[5] 
Noteworthy, for solutions containing both hindered phosphine and borane, monodimensional NMR studies generally does not show any sign of aggregation, and only advanced NMR techniques, as ${ }^{19} \mathrm{~F},{ }^{1} \mathrm{H}$ Heteronuclear Overhauser Effect spectroscopy (HOESY) or Pulsed-field Gradient Spin Echo (PGSE) experiments are able to detect and characterize the tiny amount of the adduct present in solution.[6] These studies allowed to experimentally evaluate the $\Delta \mathrm{G}^{\circ}$ of the formation of the adduct as $+0.5 \mathrm{kcal} / \mathrm{mol}$, in good agreement with molecular dynamic simulations.[7]

Since then, the topic has been extensively studied and reviewed,[8-11] and many other FLP systems has been characterized, for example based on aluminium,[12] oxygen,[13] carbon and even zirconium,[14] gold and platinum.[15,16]

Anyway, to the best of our knowledge, no selenium-based FLP is known. This element could have a great potential in the activation of small molecules, because it is open to hypervalency[17] and it is expected to form reversible bonds with acidic fragments $\left(\mathrm{H}^{+}\right.$, the carbon of $\left.\mathrm{CO}_{2} \ldots\right)$. Therefore, the energy balance between the reactants and the products could be adjusted to achieve the right conditions for catalysis.

In this paper, some Lewis pairs will be investigated by using simple and available organoselenium compounds as LB and boranes as LA. The strength and the nature of their interaction will be investigated by using the Energy Decomposition analysis (EDA) [18] which already has been useful to characterize both coordinative bonds and weak interactions. In particular, the LA and LB listed in Figure 1 will be analyzed, in different combinations. As a benchmark, a model of the wellknown $\mathrm{P}(\mathrm{Mes})_{3} \cdots \mathrm{B}\left(\mathrm{C}_{6} \mathrm{~F}_{5}\right)_{3}\left((2,6-\mathrm{Me}-\mathrm{Ph})_{3} \mathrm{P} \cdots \mathrm{B}\left(\mathrm{C}_{6} \mathrm{~F}_{5}\right)_{3}, 1 \mathrm{a}\right)$ FLP will be analyzed as well.

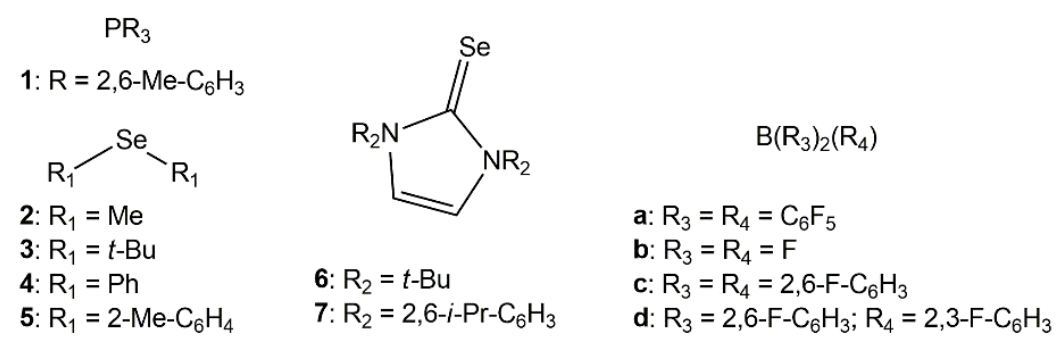

Figure 1. List of the Lewis acids and bases considered here.

Some organoselenium compounds are commercially available, as 2, $\mathbf{3}$ and $\mathbf{4}$, while many other similar compounds, even unsymmetrical, can be synthesized through different routes.[19] Also selenoureas 6 and 7 are easily prepare.[20]

\section{Results and discussion}

The EDA reveals that the interaction energy (Eint) between 1 and $\mathbf{a}$ is $-11.5 \mathrm{kcal} / \mathrm{mol}$ (Table 1), which can be decomposed in an orbital energy $\left(E_{\text {orb }}=-4.1 \mathrm{kcal} / \mathrm{mol}\right)$, a steric contribution $\left(E_{\text {st }}=\right.$ Epauli + $\mathrm{E}_{\mathrm{el}}=4.4 \mathrm{kcal} / \mathrm{mol}$ ) and a contribution given by dispersion $\left(E_{\text {disp }}=-11.8 \mathrm{kcal} / \mathrm{mol}\right)$. As it can be noted, the orbital and the steric contributions cancel each other, leaving only the dispersion forces. Noteworthy, both the fragments are little affected, as their preparation energies (Eprep, the amount of energy that the fragments have to spend to assume the geometry they show in the adduct) are 0.25 and $0.25 \mathrm{kcal} / \mathrm{mof}$ for $\mathbf{1}$ and a, respectively, leading to a dissociation energy (Eint $+E_{\text {prep}}$ ) of -11.0 $\mathrm{kcal} / \mathrm{mol}$. This value is too small to allow the complete formation of the adduct (a large, positive entropy contribution is to be considered), but it is large enough to give the system its unique properties in the activation of small molecules. This is a crucial point, as according to theoretical calculations, the $\mathrm{LA} \cdots \mathrm{H}_{2}$ and $\mathrm{LB} \cdots \mathrm{H}_{2}$ interactions are both repulsive, and therefore the presence of the adduct seems to be fundamental. ${ }^{21}$ Obviously, if the adduct is too favored or tight, any reactivity would be depressed.

Now, different selenium-based Lewis pairs will be analyzed, in order to find which combination has a similar interaction on the basis of EDA. 
Table 1. Optimized Se-B distances (in $\AA$ ) and EDA results (in $\mathrm{kcal} / \mathrm{mol}$ ) for $\mathbf{1 a}$ and $\mathbf{2} \mathbf{b}-\mathbf{7} \mathbf{b}$ adducts.

\begin{tabular}{|c|c|c|c|c|c|c|c|}
\hline Adduct & Se-B & $\mathrm{ED}_{\mathrm{D}}$ & Eprep & Eint & Eorb & $E_{\text {st }}$ & Edisp \\
\hline $1 a$ & $4.8^{\mathrm{a}}$ & -11.0 & 0.5 & -11.5 & -4.1 & 4.4 & -11.8 \\
\hline $2 a$ & 2.32 & -15.0 & 19.8 & -34.8 & -65.8 & 40.1 & -9.1 \\
\hline $2 b$ & 2.36 & -8.3 & 17.6 & -25.9 & -41.6 & 18.2 & -2.5 \\
\hline $3 a$ & 3.85 & -5.8 & 4.7 & -10.5 & -5.6 & 3.8 & -8.8 \\
\hline $3 b$ & 2.34 & -7.1 & 22.0 & -29.1 & -45.1 & 19.9 & -3.9 \\
\hline $3 c$ & 4.00 & -4.1 & 4.2 & -8.3 & -3.8 & 3.6 & -8.0 \\
\hline $3 d$ & 3.92 & -4.3 & 4.2 & -8.5 & -4.2 & 3.7 & -8.0 \\
\hline $3 e$ & 3.69 & -5.3 & 3.6 & -8.9 & -4.2 & 4.7 & -9.4 \\
\hline $4 a$ & 2.53 & -13.4 & 14.6 & -28.0 & -44.1 & 31.1 & -15.1 \\
\hline $4 b$ & 2.47 & -4.7 & 13.5 & -18.2 & -30.5 & 15.6 & -3.3 \\
\hline $5 b$ & 2.58 & -2.8 & 12.2 & -15.0 & -23.4 & 12.0 & -3.6 \\
\hline $6 b$ & 2.37 & -8.7 & 22.1 & -30.8 & -45.3 & 18.3 & -3.7 \\
\hline $7 \mathrm{~b}$ & 2.33 & -4.9 & 25.1 & -30.0 & -47.1 & 21.7 & -4.6 \\
\hline
\end{tabular}

The steric hindrance of $\mathrm{BF}_{3}(\mathbf{b})$ is generally too small to ensure the frustration by steric reasons, but frustration can arise also from electronic factors. In all cases, Eorb is quite large, indicating a strong Se-B interaction, whereas Eprep, which is almost entirely attributable to the deformation of the borane is always large. In these cases, a pronounced Lewis Pairs adduct is expected, inhibiting any reactivity toward small molecules. Anyway, some interesting trends can be noted. For example, Eint is less negative for $\mathbf{2} \mathbf{b}$ than for $\mathbf{3 b}$, despite the larger steric hindrance of the latter. This is due to the many weak $\mathrm{CH} \cdots \mathrm{F}$ interactions that are present in the optimized geometry of $\mathbf{3 b}$. The introduction of the phenyl substituent $(\mathbf{4 b})$ considerably lowers Eint to $-18.2 \mathrm{kcal} / \mathrm{mol}$. In 4 , the two phenyl moieties already repel each other, resulting in a dihedral angle C-Se-C-C of $136^{\circ}$. Adding a methyl group in ortho position, as in 5 , the interaction with $\mathbf{b}$ is still weaker $(-15.0 \mathrm{kcal} / \mathrm{mol})$, approaching the strength in the benchmark FLP (-11.5). Using cyclic selenoureas 6 and 7, Eint rises again to about $-30 \mathrm{kcal} / \mathrm{mol}$, giving strong adducts. Noteworthy, the balance between Eprep and Eint leads to quite low ED values.

Going back to the more sterically demanding borane $\mathbf{a}$, the simplest selenide $\mathbf{2}$ shows a Eint value of $-34.8 \mathrm{kcal} / \mathrm{mol}$, even more negative than in the case of $\mathbf{2} \mathbf{b}$, due to more favorable dispersion and larger orbital mixing. The resulting ED is $-15.0 \mathrm{kcal} / \mathrm{mol}$, more negative of the benchmark. But it is enough to substitute the methyl group with the bulkier tert-butyl one (3a) to make Eint fall down to $10.5 \mathrm{kcal} / \mathrm{mol}$, of which the orbital mixing is $-5.6 \mathrm{kcal} / \mathrm{mol}$, similar to that of $1 \mathbf{a}$. The preparation energy is larger, $4.7 \mathrm{kcal} / \mathrm{mol}$, mainly due to the selenium moiety. This system is a good candidate for a selenium-based FLP $(\mathrm{ED}=-5.8 \mathrm{kcal} / \mathrm{mol})$

The borane $\mathbf{c}$ and $\mathbf{d}$ attracted some attention because they allowed bench-stable FLPs,[22] allowing for easier hydrogenation procedures, whereas $\mathbf{a}$ is known to be highly moisture-sensitive. For $3 \mathbf{c}$ and $\mathbf{3 d}$, Eint is lower than in the case of $\mathbf{3 a}$, likely because of the smaller acidity of the borane. As a confirmation, Eorb is less negative, leading dispersion to be even more important than before, in percentage, and, coherently, also the Se-B distance is larger than before $(4 \AA)$, indicating a very weak association. Using the all-protonated borane $\mathbf{e}$, the energy contributions of Eint do not change sensibly. The Se-B distance becomes smaller, but the Eorb remains constant, indication of the lower acidity of the borane. Therefore, also this system is likely to give a FLP system, but the borane $\mathbf{e}$ is generally not acidic enough to give the desired reactivity.

Finally, in the case of 4a, Eint is quite high $(-28.0 \mathrm{kcal} / \mathrm{mol})$, but also Eprep is relevant $(14.6 \mathrm{kcal} / \mathrm{mol})$, leading to a promising system.

Therefore, $\mathbf{3 a}, \mathbf{3} \mathbf{c}, \mathbf{4} \mathbf{a}$ and $\mathbf{5 b}$ resulted to be the more promising systems and can be considered for the next step. The products of the activation of $\mathrm{H}_{2}$ and $\mathrm{CO}_{2}$ will be indicated with the suffices $\mathrm{H}_{2}$ and $\mathrm{CO}_{2}$, respectively.

Also in this case, we can start from $\mathbf{2 b}$ as a negative benchmark: this system is not able to activate hydrogen or carbon dioxide and starting from geometries with these small molecules between the 
selenium and the boron, they are expelled $\left(\mathbf{2} \mathbf{b H}_{2}\right.$, Figure $\left.\mathrm{S} 1\right)$ or form very weak adducts $\left(\mathbf{2} \mathbf{b C O}_{2}\right)$. Also with $\mathbf{5 b}$, the adducts disgregates into its components (Figure S1).

On the other hand, with $\mathbf{3 a}, \mathbf{3} \mathbf{c}$ and $\mathbf{4 a}$, hydrogen and carbon dioxide results to be activated, even if with different degrees (Figure 2). Details about energies and geometries of these adducts are shown in Table 2.

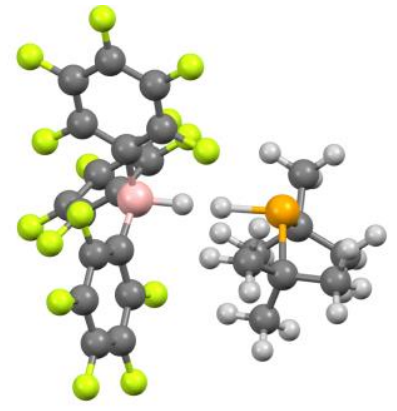

$3 \mathrm{aH}_{2}$

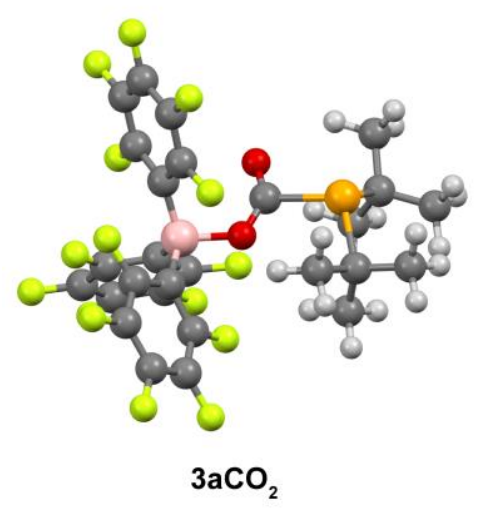

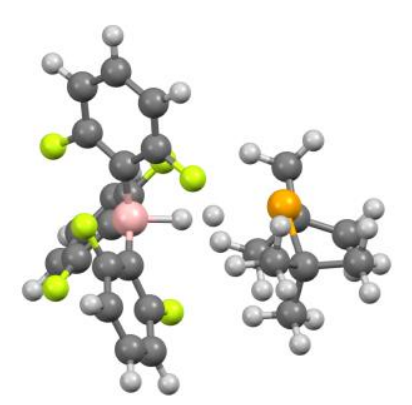

$3 \mathrm{CH}_{2}$

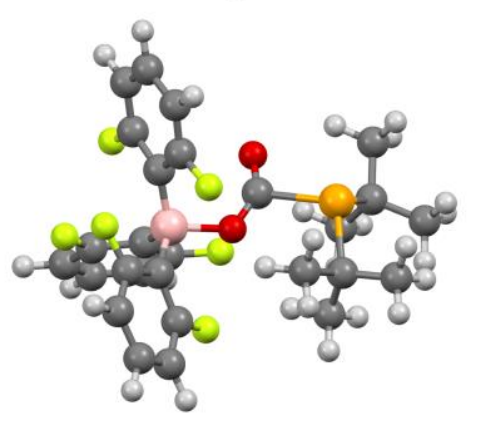

$3 \mathrm{CCO}_{2}$

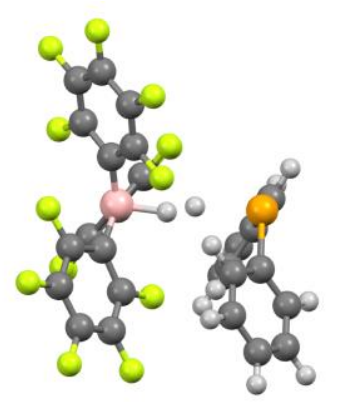

$4 \mathrm{aH}_{2}$

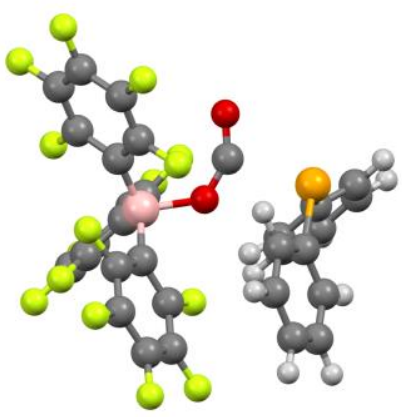

$4 \mathrm{aCO}_{2}$

Figure 2. Optimized geometries of adducts between hydrogen or carbon dioxide with selenium-based FLPs $3 a, 3 c$ and $4 a$.

Table 2. Adduct formation energy (in kcal/mol) and geometries (bond lengths in $\AA$, angles in degrees) for adducts with hydrogen and carbon dioxide.

\begin{tabular}{cccccc}
\hline Adduct & $\mathrm{H}^{\cdots} \mathrm{H}^{\mathrm{a}}$ & $\mathrm{O}^{-C}-\mathrm{O}^{\mathrm{b}}$ & $\mathrm{Se}-\mathrm{X}$ & $\mathrm{B}-\mathrm{X}$ & $\mathrm{E}^{\mathrm{f}}$ \\
\hline $\mathbf{3 a H}_{2}$ & 1.060 & - & $1.677^{\mathrm{c}}$ & $1.300^{\mathrm{c}}$ & -7.2 \\
$\mathbf{3}_{\mathbf{c H}} \mathbf{2}$ & 0.880 & - & $1.967^{\mathrm{c}}$ & $1.450^{\mathrm{c}}$ & 7.8 \\
$\mathbf{4 a H}_{2}$ & 0.855 & - & $2.007^{\mathrm{c}}$ & $1.491^{\mathrm{c}}$ & 8.4 \\
$\mathbf{3 a C O}_{2}$ & - & 137.8 & $2.156^{\mathrm{d}}$ & $1.628^{\mathrm{e}}$ & -3.6 \\
$\mathbf{3}_{\mathbf{c} C \mathrm{CO}_{2}}$ & - & 141.0 & $2.218^{\mathrm{d}}$ & $1.671^{\mathrm{e}}$ & 2.7 \\
$\mathbf{4} \mathbf{a C O}_{2}$ & - & 147.3 & $2.359^{\mathrm{d}}$ & $1.709^{\mathrm{e}}$ & 12.2 \\
\hline
\end{tabular}

a Bond length in isolated $\mathrm{H}_{2}=0.751 \AA$; ${ }^{\mathrm{b}} \mathrm{O}-\mathrm{C}-\mathrm{O}$ angle in isolated $\mathrm{CO}_{2}=180^{\circ} ;{ }^{\mathrm{c}} \mathrm{X}=\mathrm{H} ;{ }^{\mathrm{d}} \mathrm{X}=\mathrm{C} ;{ }^{\mathrm{e}} \mathrm{X}=\mathrm{O} ;{ }^{\mathrm{f}}$ with respect to the FLP and hydrogen or carbon dioxide.

In all these cases, in the adduct the hydrogen bond results to be longer than its natural value and the carbon dioxide is markedly bent, confirming their "activation". 3a is the most promising system, either using a weaker borane (3c) or a less nucleophilic selenium (4a) results in a less stable final adduct. Indeed, for all of them the Gibbs energy of the activated adduct is too high to ensure a stoichiometric activation, but it could be accessible as an intermediate species, for example using the FLP as a catalyst in a hydrogenation cycle.

\section{Conclusions}

In summary, different selenium-based Lewis adducts have been analyzed, in terms of DFToptimized geometry and interaction energy, and compared with a well-known Frustrated Lewis 
Pairs, in order to check whether it would be possible to have a selenium-based FLP system. It has been shown that tuning both the steric and electronic properties of the selenium and the borane moieties, FLP should be likely possible, in some cases also without the need of strictly anhydrous conditions. The reactivity of the most promising candidates in the activation of hydrogen and carbon dioxide has been studied, as well, concluding that probably selenium-based FLP system are not able to stoichiometrically activate $\mathrm{H}_{2}$ and $\mathrm{CO}_{2}$, but they have a potential as catalysts (especially the pair $\left.\mathrm{Se}(\mathrm{tBu})_{3}-\mathrm{B}\left(\mathrm{C}_{6} \mathrm{~F}_{5}\right)_{3}\right)$, for example in transfer hydrogenation or $\mathrm{CO}_{2}$ capture and utilization cycles.

Supplementary Materials: The following are available online at http://www.xxxxx, Figure S1: Optimized geometries of adducts between hydrogen or carbon dioxide with selenium-based FLPs $\mathbf{2} \mathbf{b}$ and $\mathbf{5 b}$, list of all the optimized geometries.

Funding: This research received no external funding.

Conflicts of Interest: The authors declare no conflict of interest.

\section{Appendix A}

Computational Details: All the structures have been optimized with ORCA,[23] by using the PBE functional. For heavy atoms, relativistic effects have been taken into account by using ZORA and the ZORATZVP basis set.[24] Dispersion effects have been modelled by using the Grimme's D3 correction with BJ damping.[25] The solvent effect has been considered by the conductor-like polarizable continuum model, CPCM, as implemented in ORCA (solvent dichloromethane).

The Energy Decomposition Analysis[18] has been carried out using the same computational details.

\section{References}

1 Brown, H. C.; Schlesinger, H. I.; Cardon, S. Z. Studies in Stereochemistry. I. Steric Strains as a Factor in the Relative Stability of Some Coordination Compounds of Boron. J. Am. Chem. Soc. 1942, 64, 325-329.

Damico, R.; Broaddus, C. D. Hydride Transfer. Reactions of Triphenylcarbonium Fluoroborate and Triphenylmethyl Bromide with Tertiary Amines. J. Org. Chem. 1966, 31, 1607-1612. Stephan, D. W. Frustrated Lewis Pairs: A New Strategy to Small Molecule Activation and Hydrogenation Catalysis. J. Chem. Soc. Dalt. Trans. 2009, 17, 3129-3136.

Welch, G. C.; San Juan, R. R.; Masuda, J. D.; Stephan, D. W. Reversible, Metal-Free Hydrogen Activation. Science 2006, 314, 1124-1126.

Welch, G. C.; Stephan, D. W. Facile Heterolytic Cleavage of Dihydrogen by Phosphines and Boranes. J. Am. Chem. Soc. 2007, 129, 1880-1881.

Rocchigiani, L.; Ciancaleoni, G.; Zuccaccia, C.; MacChioni, A. Probing the Association of Frustrated Phosphine-Borane Lewis Pairs in Solution by NMR Spectroscopy. J. Am. Chem. Soc. 2014, 136, 112-115. Bakó, I.; Stirling, A.; Bálint, S.; Pápai, I. Association of Frustrated Phosphine-Borane Pairs in Toluene: Molecular Dynamics Simulations. Dalt. Trans. 2012, 41, 9023-9025. Stephan, D. W.; Erker, G. Frustrated Lewis Pairs: Metal-Free Hydrogen Activation and More. Angewandte Chemie - International Edition. John Wiley \& Sons, Ltd, January 4, 2010, pp 46-76. Rocchigiani, L. Experimental Insights into the Structure and Reactivity of Frustrated Lewis Pairs. Israel Journal of Chemistry. Wiley-VCH Verlag, February 1, 2015, pp 134-149.

10 Stephan, D. W.; Erker, G. Frustrated Lewis Pair Chemistry: Development and Perspectives. Angew. Chemie - Int. Ed. 2015, 54, 6400-6441.

11 Lam, J.; Szkop, K. M.; Mosaferi, E.; Stephan, D. W. FLP Catalysis: Main Group Hydrogenations of Organic Unsaturated Substrates. Chemical Society Reviews. Royal Society of Chemistry, July 7, 2019, pp 3592-3612. 
Lewis Pairs and Ammonia Borane. J. Am. Chem. Soc. 2010, 132, 1796-1797.

Mahdi, T.; Stephan, D. W. Enabling Catalytic Ketone Hydrogenation by Frustrated Lewis Pairs. J. Am. Chem. Soc. 2014, 136, 15809-15812.

Budzelaar, P. H. M.; Hughes, D. L.; Bochmann, M.; Macchioni, A.; Rocchigiani, L. H2 Activation by Zirconaziridinium Ions: $\sigma$-Bond Metathesis: Versus Frustrated Lewis Pair Reactivity. Chem. Commun. 2020, 56, 2542-2545.

Hidalgo, N.; Moreno, J. J.; Pérez-Jiménez, M.; Maya, C.; López-Serrano, J.; Campos, J. Evidence for Genuine Bimetallic Frustrated Lewis Pair Activation of Dihydrogen with Gold(I)/Platinum(0) Systems. Chem. - A Eur. J. 2020, 26, 5982-5993.

16 Scott, D. J.; Fuchter, M. J.; Ashley, A. E. Designing Effective "frustrated Lewis Pair" Hydrogenation Catalysts. Chemical Society Reviews. Royal Society of Chemistry, October 7, 2017, pp 5689-5700.

Drabowicz, J.; Kiełbasiński, P.; Zajac, A. Hypervalent Derivatives of Selenium and Tellurium. In PATAI'S Chemistry of Functional Groups; John Wiley \& Sons, Ltd: Chichester, UK, 2011.

18 Hopffgarten, M. von; Frenking, G. Energy Decomposition Analysis. Wiley Interdiscip. Rev. Comput. Mol. Sci. 2012, 2, 43-62.

19 Saba, S.; Botteselle, G. V.; Godoi, M.; Frizon, T. E. A.; Galetto, F. Z.; Rafique, J.; Braga, A. L. CopperCatalyzed Synthesis of Unsymmetrical Diorganyl Chalcogenides (Te/Se/S) from Boronic Acids under Solvent-Free Conditionsł. Molecules 2017, 22, 1367.

20 Liske, A.; Verlinden, K.; Buhl, H.; Schaper, K.; Ganter, C. Determining the $\pi$-Acceptor Properties of nHeterocyclic Carbenes by Measuring The77Se NMR Chemical Shifts of Their Selenium Adducts. Organometallics 2013, 32, 5269-5272.

Rokob, T. A.; Hamza, A.; Stirling, A.; Soós, T.; Pápai, I. Turning Frustration into Bond Activation: A Theoretical Mechanistic Study on Heterolytic Hydrogen Splitting by Frustrated Lewis Pairs. Angew. Chemie - Int. Ed. 2008, 47, 2435-2438.

Gyömöre, Á.; Bakos, M.; Földes, T.; Pápai, I.; Domján, A.; Soós, T. Moisture-Tolerant Frustrated Lewis Pair Catalyst for Hydrogenation of Aldehydes and Ketones. ACS Catal. 2015, 5, 5366-5372.

23 Neese, F. Software Update: The ORCA Program System, Version 4.0. Wiley Interdiscip. Rev. Comput. Mol. Sci. 2017, 8, e1327.

24 Van Lenthe, E. Geometry Optimizations in the Zero Order Regular Approximation for Relativistic Effects. J. Chem. Phys. 1999, 110 (18), 8943-8953.

25 Grimme, S.; Ehrlich, S.; Goerigk, L. Effect of the Damping Function in Dispersion Corrected Density Functional Theory. J. Comput. Chem. 2011, 32, 1456-1465.

Publisher's Note: MDPI stays neutral with regard to jurisdictional claims in published maps and institutional affiliations.

(C) 2020 by the authors. Submitted for possible open access publication under the terms and conditions of the Creative Commons Attribution (CC BY) license (http://creativecommons.org/licenses/by/4.0/). 